\title{
Endoscopic ultrasound-guided gallbladder drainage after real-time assessment of cystic duct exclusion following biliary placement of an uncovered metal
}

An 80-year-old patient was admitted because of abdominal pain, vomiting, recent-onset diabetes, and weight loss. Computed tomography (CT) and endoscopic ultrasound (EUS) allowed diagnosis of a 5-cm adenocarcinoma of the pancreatic head, with liver metastasis and obstructive jaundice. Endoscopic retrograde cholangiopancreatography (ERCP) was performed with a 4-cm partially covered self-expanding metal stent (SEMS). Due to persistent discomfort and pain, ultrasonography was performed and showed gallbladder hydrops.

Replacement of the partially covered SEMS with an uncovered SEMS was planned. An initial EUS confirmed an 11-cm-long hydropic gallbladder. The partially covered stent was removed without any bile flow. Contrast injection depicted a slightly dilated cystic duct originating in the center of the stenosis ( Fig.1). A 4-cm uncovered SEMS was placed, after which the cystic duct was no longer contrast-injectable or cannulable.

During the same procedure a new EUS was performed that showed a persistently hydropic gallbladder without any sign of bile flow, demonstrating cystic duct exclusion by the SEMS with clearly visible neoplastic infiltration (> Fig.2). EUSguided gallbladder drainage with a small-caliber $(8 \mathrm{~mm})$ electrocautery-enhanced lumen-apposing metal stent (LAMS) was decided upon, and this resulted in complete emptying of the gallbladder ( $\vee$ Video 1 ; Fig.3, $>$ Fig.4). Postprocedural follow-up was uneventful and the patient was discharged 2 days later. Restaging CT at 30 days showed a patent LAMS without any complication ( Fig. 5).
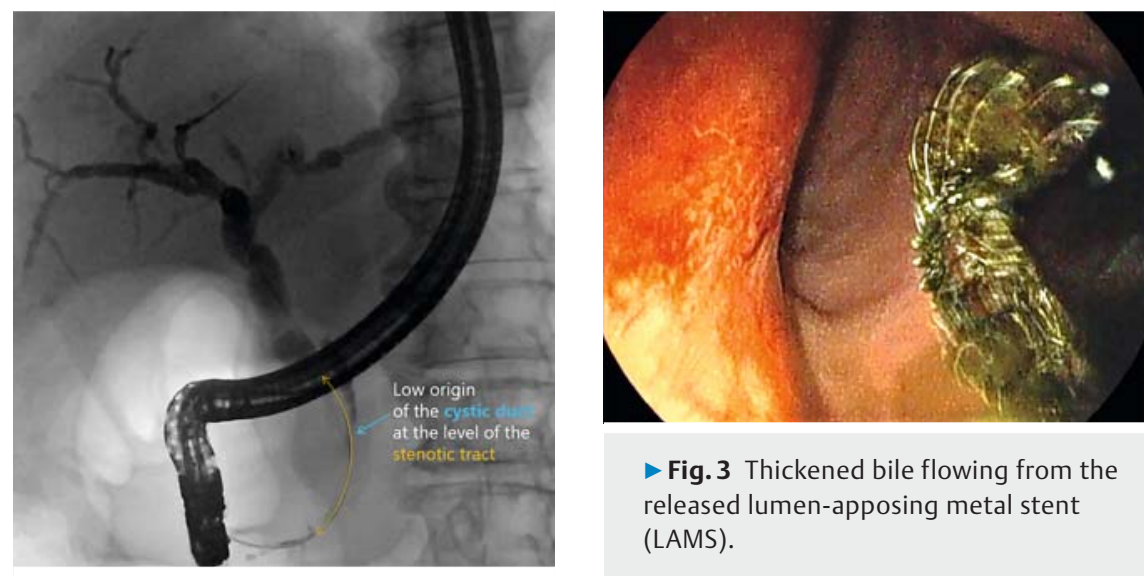

- Fig. 3 Thickened bile flowing from the released lumen-apposing metal stent (LAMS).

- Fig. 1 Contrast injection showing stenosis of the common bile duct and a dilated cystic duct originating in the middle of the stenotic tract.

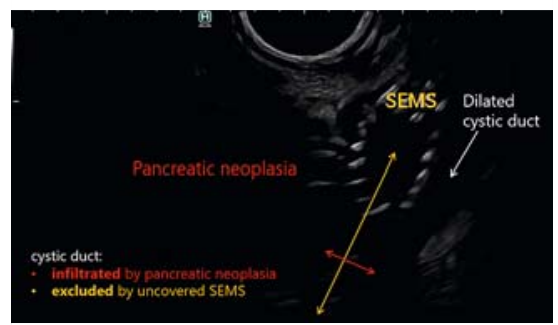

- Fig. 2 Endoscopic ultrasound showing a dilated cystic duct (white arrow) due to compression by the self-expanding metal stent (SEMS; yellow arrow) and infiltration by pancreatic neoplasia (red arrow).

EUS-guided gallbladder drainage is the modality of choice for relief of cholecystitis in patients unfit for surgery [1]. Obstructive cholecystitis may complicate around $15 \%$ of SEMS placements [2]. Its occurrence seems unrelated to whether the SEMS is covered or uncovered [3], and to be favored by neoplastic infiltration of the cystic duct $[2,4]$. Although 


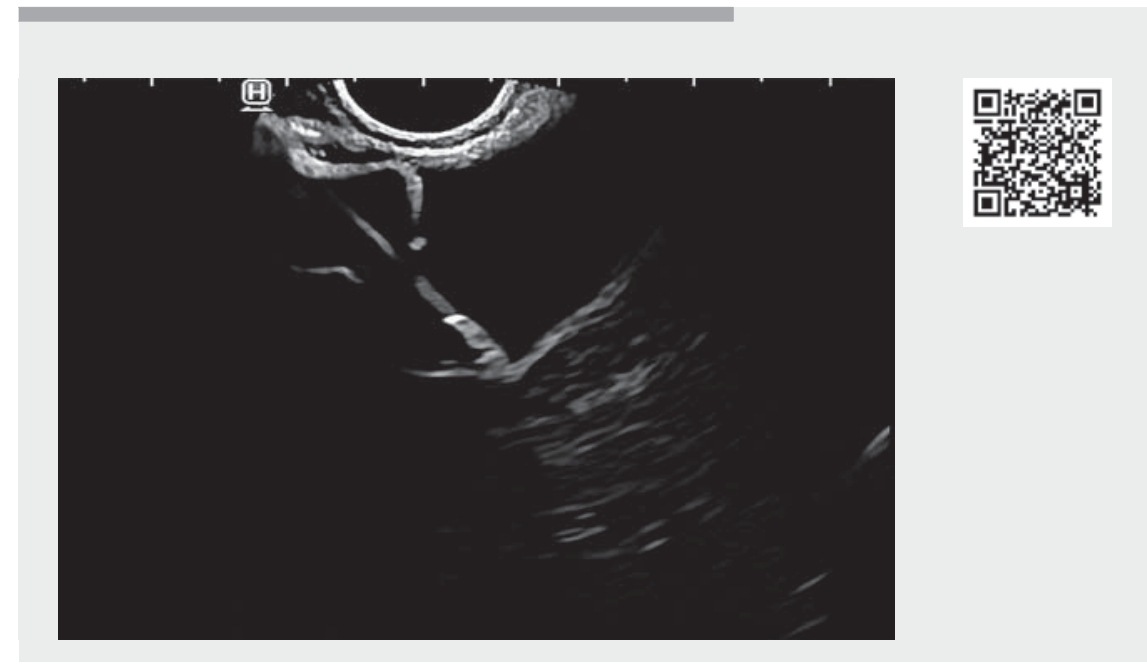

$\checkmark$ Video 1 Endoscopic ultrasound-guided drainage of a hydropic gallbladder after realtime assessment of functional exclusion of the cystic duct caused by neoplastic infiltration of the cystic duct and worsened by placement of an uncovered self-expanding biliary metal stent.

EUS-guided drainage has been proposed for use in this scenario, it has been described only after development of acute cholecystitis [2]. We report for the first time a real-time assessment of cystic duct exclusion after SEMS placement, which was unchanged after the partially covered SEMS was replaced by an uncovered SEMS, and was finally relieved by placement of an 8-mm LAMS during the same procedure.

Endoscopy_UCTN_Code_TTT_1AS_2AD

\section{Competing interests}

The authors declare that they have no conflict of interest.

\section{The authors}

\section{Giuseppe Vanella Matteo Tacelli, Maria} Chiara Petrone, Paolo Giorgio Arcidiacono Pancreatobiliary Endoscopy and Endosonography Division, Pancreas Translational and Clinical Research Center, IRCCS San Raffaele Scientific Institute, Milan, Italy
Corresponding author

\section{Paolo Giorgio Arcidiacono, MD}

Pancreatobiliary Endoscopy and EUS

Division, Pancreas Translational and Clinical Research Center, San Raffaele Scientific Institute, Via Olgettina 60, 20132 Milan, Italy arcidiacono.paologiorgio@hsr.it

\section{References}

[1] Teoh AYB, Kitano M, Itoi T et al. Endosonography-guided gallbladder drainage versus percutaneous cholecystostomy in very highrisk surgical patients with acute cholecystitis: an international randomised multicentre controlled superiority trial (DRAC 1). Gut 2020; 69: 1085-1091. doi:10.1136/gutjnl2019-319996

[2] Jung JH, Park SW, Hyun B et al. Identification of risk factors for obstructive cholecystitis following placement of biliary stent in unresectable malignant biliary obstruction: a 5 -year retrospective analysis in single center. Surg Endosc 2020. doi:10.1007/s00464020-07694-2

[3] Seo DW, Sherman S, Dua KS et al. Covered and uncovered biliary metal stents provide similar relief of biliary obstruction during neoadjuvant therapy in pancreatic cancer: a randomized trial. Gastrointest Endosc 2019; 90: 602-612.e4. doi:10.1016/j. gie.2019.06.032

[4] Takinami M, Murohisa G, Yoshizawa Y et al. Risk factors for cholecystitis after stent placement in patients with distal malignant biliary obstruction. J Hepatobiliary Pancreat Sci 2020; 27: 470-476. doi:10.1002 jhbp.767

Bibliography

Endoscopy 2021; 53: E459-E460

DOI 10.1055/a-1346-7645

ISSN 0013-726X

published online 4.2.2021

(c) 2021. Thieme. All rights reserved.

Georg Thieme Verlag KG, Rüdigerstraße 14, 70469 Stuttgart, Germany

\section{ENDOSCOPY E-VIDEOS}

https:/|eref.thieme.de/e-videos

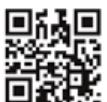

Endoscopy E-Videos is a free access online section, reporting on interesting cases and new

techniques in gastroenterological endoscopy. All papers include a high quality video and all contributions are freely accessible online.

This section has its own submission website at https://mc.manuscriptcentral.com/e-videos 